\title{
Review Article \\ Development of Novel Corrosion Techniques for a Green Environment
}

\author{
Zaki Ahmad and Faheemuddin Patel \\ Mechanical Engineering Department, King Fahd University of Petroleum \& Minerals (KFUPM), Dhahran 31261, Saudi Arabia
}

Correspondence should be addressed to Faheemuddin Patel, faheemmp@kfupm.edu.sa

Received 4 March 2011; Accepted 3 July 2011

Academic Editor: Peter C. Okafor

Copyright (๑) 2012 Z. Ahmad and F. Patel. This is an open access article distributed under the Creative Commons Attribution License, which permits unrestricted use, distribution, and reproduction in any medium, provided the original work is properly cited.

\begin{abstract}
The synergistic effect of air pollution, brown clouds and greenhouse gasses is deleterious to human health and industrial products. The use of toxic inhibitors, chemicals in water treatment plants, and anti-fouling agents in desalination plants has contributed to the greenhouse effect. Conventional anti-corrosion techniques such as paints, coatings, inhibitor treatments, and cathodic protection paid no regard to greenhouse effect. Work on eco-friendly anti-corrosion techniques is scanty and largely proprietary. The use of nano- $\mathrm{TiO}_{2}$ particles introduced in alkyds and polyurethane-based coatings showed a higher corrosion resistance compared to conventional $\mathrm{TiO}_{2}$ coatings with significant photocatalytic activity to kill bacteria. The use of UV radiations for photoinhibition of stainless steel in chloride solution can replace toxic inhibitors. Corrosion inhibition has also been achieved by using natural materials such as polymers instead of toxic chemical inhibitors, without adverse environmental impact. $\mathrm{TiO}_{2}$ films exposed to UV radiation have shown the capability to protect the steel without sacrificing the film. Self-healing materials with encapsulated nanoparticles in paints and coatings have shown to heal the defects caused by corrosion. These innovative techniques provide a direction to the corrosion scientists, engineers, and environmentalists who are concerned about the increasing contamination of the planet and maintaining a green environment.
\end{abstract}

\section{Introduction}

The deterioration of materials and equipment by atmospheric pollution is not a new phenomenon and the corrosion engineers developed appropriate strategies to combat atmospheric corrosion. However, in the last decade global warming has placed heavy responsibilities on engineers and scientists to transform the conventional production processing techniques into eco-friendly techniques to control the greenhouse effect, which is slowly, but surely, inflicting an irreversible damage to materials and mankind on this planet. Whereas air pollution commonly refers to aerosols containing suspended impurities of particles such as sulfates, nitrates, organic compounds, and fly-ash particles, the green house gases contain mainly carbon dioxide $\left(\mathrm{CO}_{2}\right)$, methane $(\mathrm{CH})$, nitric oxide and nitrogen dioxide $\left(\mathrm{NO}_{x}\right)$, sulfur $(\mathrm{s})$, and chlorofluorocarbons (CFCs). Typical aerosols contain $25 \%$ sulfate, $11 \%$ organic, $9 \%$ BC, $6 \%$ nitrates, and $18 \%$ other materials. The Indian Ocean Experiment (INDOEX) conducted during 1996-1999 showed that the aerosols over the oceans show typically $1 \%$ sea salts and $10 \%$ mineral dust (Figure 1).

Brown clouds containing dangerous levels of aerosols observed in Asia have a tendency to increase global warming by as much as $50 \%$ [1]. The atmosphere is reported to be warming at a rate of $0.25^{\circ} \mathrm{C}$ per decade since 1950 at altitudes higher than $2-5 \mathrm{Km}$ above sea level [2]. These brown clouds appear to have the same effect as green house gases. In context of corrosion, both green house gases and brown clouds have a deleterious effect on the integrity of buildings, vehicles, cultural monuments, and all engineered products. In the Euro-zone, 12 billion Euros are lost annually by deterioration of buildings [3]. The corrosion prevention practices are like a double-edged weapon; they stop corrosion, but the chemicals and materials used in corrosion prevention techniques interact with the atmosphere and add to environmental pollution. Corroded objects act synergistically to elevate pollution. Several metal ions interact with organic 


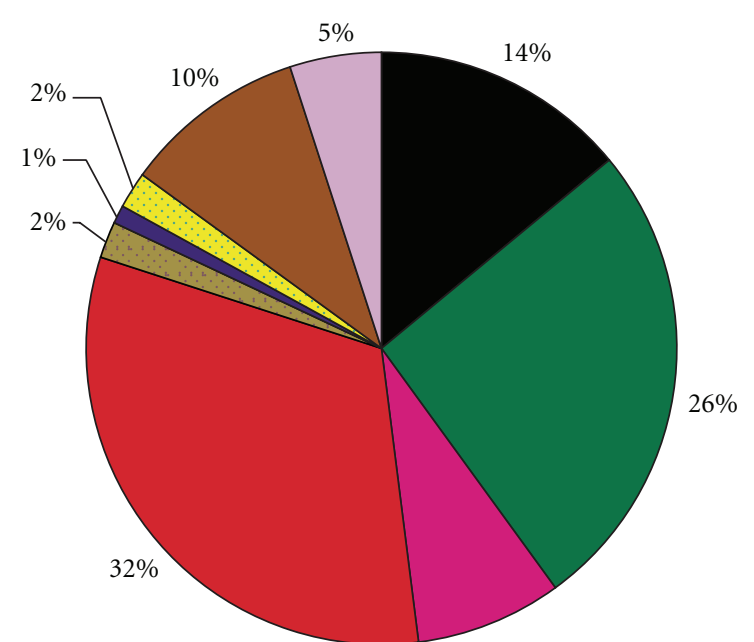

$8 \%$

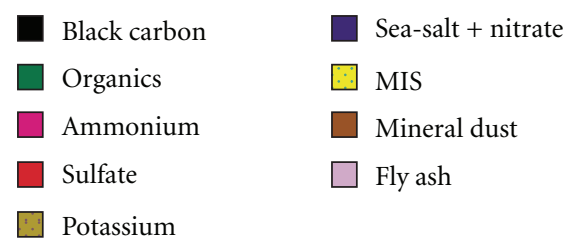

FIgURE 1: Fractional contribution of chemical components to the INDOEX aerosol, as measured over the Indian Ocean by aircraft in February and March 1999 [1].

compounds like humic acid and retard photocatalytic oxidation [4]. Corrosion prevention practices applied to power plants, desalination plants, transportation, aerospace, gas, oil, petrochemical and construction industries need to be modified to keep the environment green. No formal ecofriendly corrosion protection techniques have been reported by professional corrosion organizations. The results obtained by the authors from their previous work and some work reported in the literature have prompted them to present an overview of some eco-friendly corrosion techniques which could be improved further to save the planet from the green house and brown clouds effect. In spite of media mouth press and Bush administration's rejection of global warming caused by carbon levels, Norway has rebuffed the attempt by installing third generation carbon sequestration in the North Sea. The USA has fallen behind in this critical technology.

\section{Eco-Friendly Techniques and Their Applications}

2.1. Desalination Plants. Saudi Arabia is now the largest producer of desalinated water in the world. It houses 30 desalination plants with a production capacity of million gallons of water per day. It produces $28 \times 10^{6} \mathrm{MW} / \mathrm{hour}$ of electricity. These plants contribute to air pollution with the release of 282,955 thousand metric tons of $\mathrm{CO}_{2}$ [5]. The shift from traditional designs to eco-friendly design is shown by Carlsbad (California, USA) desalination plant. It has been designed to produce $13.5 \mathrm{~kW} / 5000$ gallons of drinking water [6]. This plant is designed to reduce green house carbon footprints by energy-efficient design, clean corrosion protection techniques, use of $\mathrm{CO}_{2}$ for water production, $\mathrm{CO}_{2}$ sequestration, and using warm water sources. By using warm cooling water, additional electrical energy savings of $12,208 \mathrm{MWH} / \mathrm{yr}$ and carbon dioxide footprint of 30,565 tons/year are predicted to be achieved. Clean water and superhydrophobic surfaces in heat exchanger tubes would have the capabilities to keep the tube surface ultraclean. Waste $\mathrm{CO}_{2}$ releasing from chemical or other industries may be used in the desalination plants to make the design more eco-friendly. The above measures would reduce pollution in an area inflicted by one of the harshest environments with dangerous levels of aerosols.

2.2. Water Filtration. Water quality directly affects the magnitude of corrosion. Replacement of old techniques by new technologies such as vibratory sheer enhanced technology (VSEP) has made it possible to produce clean water from reverse osmosis rejects by removing TOC (total organic compounds), TSS (total suspended solids), and TDS (total dissolved solids) content which induces corrosion and biofouling by formation of colloidal suspension [7]. A fluid dynamics comparison between crossflow filtration and vibratory shear enhanced process (VSEP) is shown in Figure 2, and a schematic of VSEP is shown in Figure 3. The VSEP technology is mature, proven, and cost-effective [8].

2.3. New Eco-Friendly Surface Modification Techniques. In corrosion prevention methods, coating is most widely practiced but it has aroused serous concerns because of its effect on environmental pollution. New environmental regulations focus on reducing the volatile organic compounds (VOCs) in paints which have the highest ozone-forming potential. The breakdown of coating under ultraviolet radiation and harsh environment necessitated the development of nanocoatings. Lotus flower, which remains clean in polluted water, provided a stimulus for the development of nanocoatings, which are corrosion resistant with dust and water repulsion properties. In a recent work by authors [9], nanoparticles of $\mathrm{TiO}_{2}$ were introduced in alkyd resin binder in a ratio of $21: 37$ and blended in a high-speed dispersion mill. These paints were subjected to UV radiation, salt spray, and dust and water repulsion tests as specified by ASTM. After exposure to the above tests, it was observed that the nanotitanium dioxide coatings (Figure 4) showed a higher corrosion resistance with excellent water and dust repulsion properties and an outstanding resistance to ultraviolet radiation. These coatings showed a $90 \%$ reduction in coliform bacterial population due to their photocatalytic activity.

Most of the work on nanocoatings is proprietary and still in developing stages. The nanocoatings have opened a new gateway to contribute to a clean environment. Corrosion studies on nanostructured plasma-sprayed titanium dioxide and nanoalumina/titania coatings showed that these coatings offer an excellent barrier to erosion-corrosion in harsh environments such as encountered in pulp and paper industry [10]. A recent work has showed a high resistance to erosioncorrosion in $3.5 \mathrm{wt} \% \mathrm{NaCl}$ containing polystyrene particles 




(a)

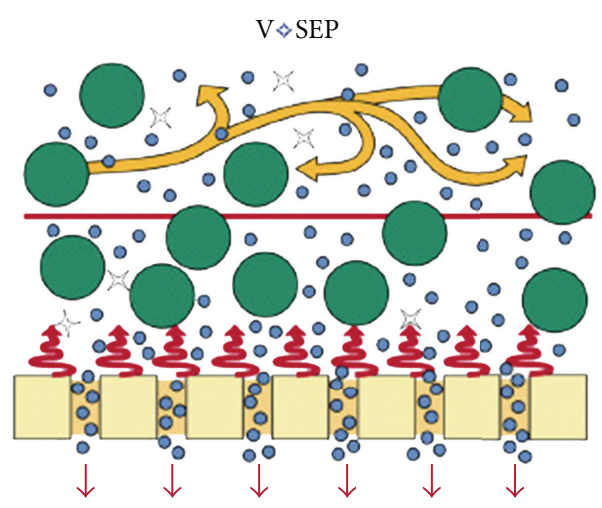

(b)

FIGURE 2: A Comparison of conventional treatment methods and VSEP: a vibrating membrane filtration system, VSEP treatment of RO reject from brackish well water [8].

TABLE 1: Comparison of conventional and nano coatings.

\begin{tabular}{lccc}
\hline Properties & $\begin{array}{c}\text { Conventional } \\
\text { alumina/titania }\end{array}$ & $\begin{array}{c}\text { Nanostructured } \\
\text { alumina/titania }\end{array}$ & Improvement \\
\hline Toughness & Poor & Excellent & Dramatic \\
\hline $\begin{array}{l}\text { Hardness } \\
(\mathrm{VHN})\end{array}$ & 1,000 & 1,000 & - \\
\hline $\begin{array}{l}\text { Wear } \\
\text { resistance } \\
\left(\mathrm{N} * \mathrm{~m} / \mathrm{mm}^{3}\right)\end{array}$ & $7.5 \times 10^{3}$ & $40 \times 10^{3}$ & $\sim 5 \mathrm{X}$ \\
\hline $\begin{array}{l}\text { Corrosion } \\
\text { resistance }\end{array}$ & Good & Exceptional & Significant \\
\hline $\begin{array}{l}\text { Grindability } \\
\text { Fatigue life }\end{array}$ & Poor & Excellent & Dramatic \\
\hline $\begin{array}{l}\text { Flex } \\
\text { tolerance }\end{array}$ & $\begin{array}{c}\text { Result in coating } \\
\text { spallation }\end{array}$ & $\begin{array}{c}\text { Can be bent over } \\
180 \text { degrees with } \\
\text { out spallation }\end{array}$ & Dramatic \\
\hline $\begin{array}{l}\text { Bond } \\
\text { strength } \\
\text { (psi) }\end{array}$ & 1,900 & $\sim 8000$ & $>10 \mathrm{X}$ \\
\hline
\end{tabular}

and a good photocatalytic activity [11]. The behavior of these coatings is dictated by the geometry of splat lamellae, volume percentage of unmelted particles, degree of residual porosity, and interlamellar spacing. A narrow interlamellar spacing prevents water penetration, and hence, erosion corrosion. Schematic of erosion-corrosion phenomenon in nanostructured coating is shown in Figure 5. The nanostructured $\mathrm{TiO}_{2}$ plasma-sprayed coatings are eco-friendly and showed a higher corrosion resistance than their conventional counterparts [12]. Table 1 shows the advantages of nanocoatings over conventional coatings.

2.4. Development of Innovative Surfaces. Environmental consideration is a prerequisite to an eco-friendly design. Galvanizing was a global choice because of longer life of steel; however, with the advances in nanocoatings with photoreactivity the choices have been broadened. A marked progress has been observed in recent years in fabrication of engineered surfaces, for example, hydrophobic surfaces. The authors have recently published a comprehensive review on fabrication of superhydrophobic surfaces [13]. The superhydrophobic surfaces possess excellent photocatalytic, water and dust repulsion, and corrosion resistance characteristics, and they represent the state-of-art eco-friendly corrosion protection techniques.

Two methods have been utilized to fabricate hydrophobic surfaces, modifying a rough surface with low energy compounds and roughening low surface energy materials. The water and dust repellency properties of such surfaces make them highly promising for a wide spectrum of applications in paints, coatings, photovoltaic cells, lubricants, electronic devices, biomaterials, prosthesis implants and a host of micro/nano-electromechanical devices. The secret of superhydrophobicity lies in its unique two-level hierarchical surface comprising of nanobumps and microhills (valleys and troughs) embedded with epicuticular nanowax crystals as shown in Figure 6. Figure 7 shows the water drop rolling on lotus leaves without sticking and taking the dirt away due to superhydrophobicity.

Water contact angles are formed between the water droplets and substrate as shown in Figure 8. For a superhydrophobic surface the water contact angles must be between 150 and $180^{\circ}$. Maximum angle of $180^{\circ}$ has been obtained by different techniques. At angles greater than $120^{\circ}$ the water drops roll through the troughs and carry away the dust particles from the surface as shown in Figure 9.

Low-surface materials such as tetrafluoroethylene (Teflon), polydimethylsiloxane (PDMS), polyamides, polycarbonates, $\mathrm{ZnO}$, and $\mathrm{TiO}_{2}$, have been used to fabricate superhydrophobic surfaces. Techniques such as laser etching [14], sol-gel [15, 16], and chemical etching [17] have been used to modify rough surface. These superhydrophobic surfaces keep corrosion at bay by not allowing a large volume of water to interact with the active surface. These surfaces can also be made to switch from a hydrophobic to a hydrophilic state. A hydrophilic surface can be used to separate oil from water. A stainless steel mesh coated with 


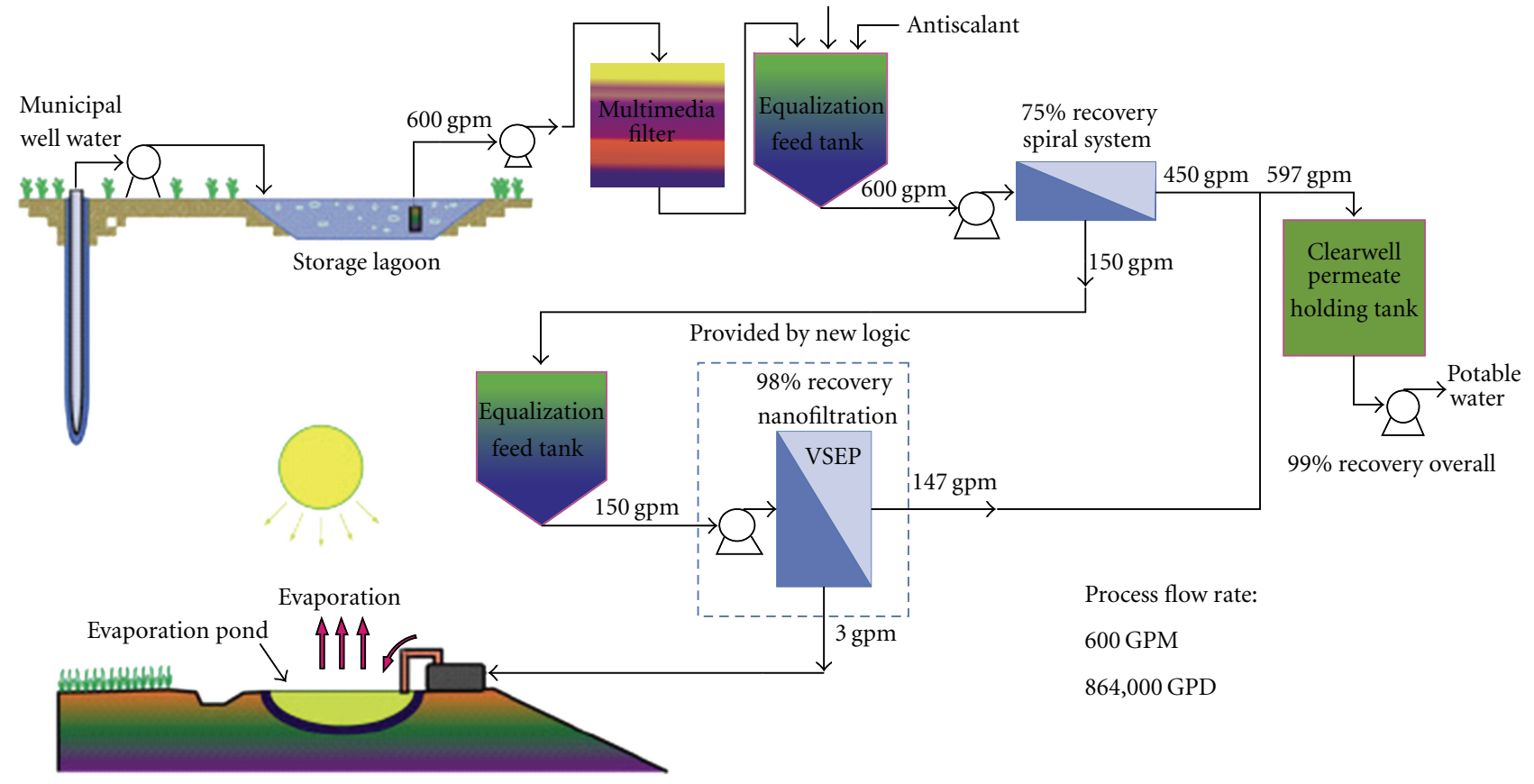

FIGURE 3: VSEP process schematic for pilot tested RO reject application [8].

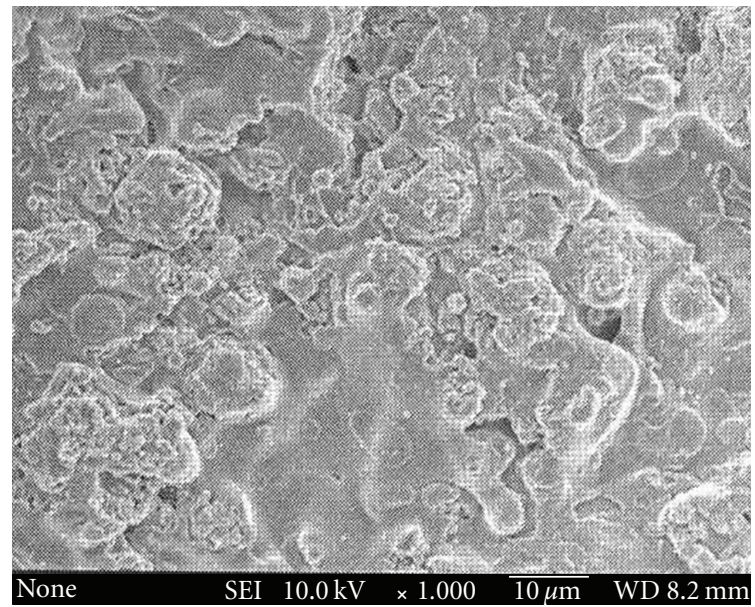

FIGURE 4: Surface of the sprayed nanotitanium dioxide coating [9].

nanofibers of polyvinyl acetates has been successfully utilized to separate oil from water [18].

2.5. Self-Healing Materials and Surfaces. Recent attempts to create self-healing surfaces are directed to increase the life of engineered structures, which do not require periodic repairs or replacements over a long period of designed service life. An electroplated coating can be made more durable by encapsulating healing agents like chromium and zinc. In principle, capsules containing a healing agent (Figure 10) are embedded in a polymer. When the material is damaged, the capsules rupture and release the repairing agent (Figure 11).
One serious problem, which contributes to environmental pollution, is concrete corrosion. To tackle this problem, hollow and porous fibers filled with adhesive liquids are embedded in concrete. As soon as a crack appears the liquid is released to heal the crack. Delivering a healing agent from a remote reservoir to the damaged region via a vascular network housed in a honeycombed structure offers the potential of robust and sustainable system. Aeronautical and automobile companies are developing autonomous system that triggers the repair mechanism upon the onset of damage to retain the structural integrity and the service life without hurting the environment. A schematic of controlled release is shown in Figure 12. 


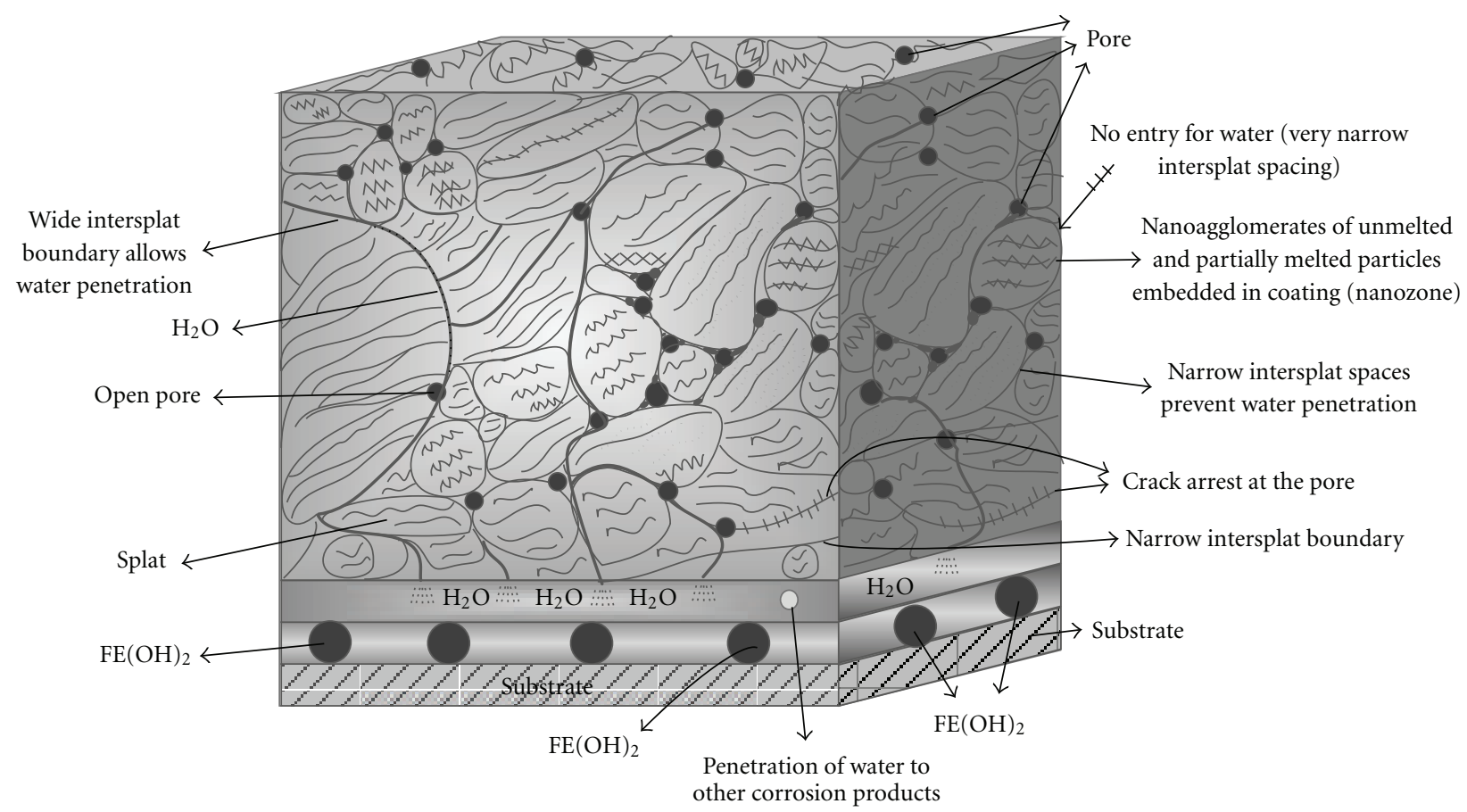

FIgURE 5: Erosion-corrosion phenomenon in nanostructured coating.

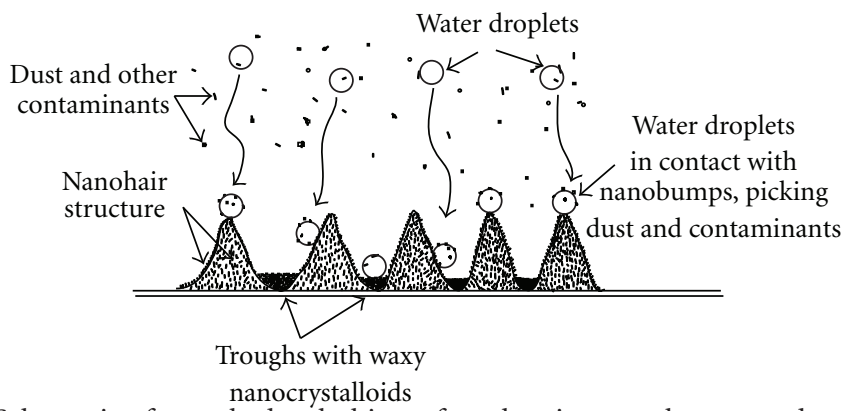

FIGURE 6: Schematic of superhydrophobic surface showing nanobumps and waxy troughs.

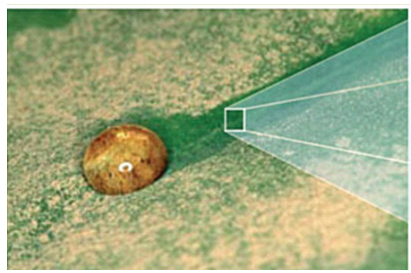

(a)

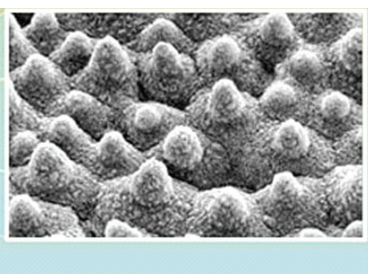

(b)
Figure 7: (a) Water rolls across a leaf without sticking at all and carries away dirt; (b) microscopic bumps (a few microns in size) all across the leaf's surface hold the key to its water-repelling properties.

2.6. Corrosion Inhibition and Cathodic Systems. Severe damage to environment has been caused over the years by the use of organic and inorganic inhibitors in oil and gas and water treatment plants. Inorganic inhibitors like chromates, nitrates, phosphates, and silicates, organic inhibitors like monoamines and diamines, synthetic inhibitors like chromophosphates, and scavenges like sodium sulfate have been indiscriminately used without regard to environmental pollution. Recent eco-friendly methods used in this regard include photo-induced inhibition of 304SS in sodium chloride by UV radiations. It has been shown that UV radiation has a significant effect in corrosion prevention [19]. Ultraviolet radiation has also been utilized to provide cathodic protection of steel structures in the presence of semiconductor films like $\mathrm{TiO}_{2}$. Recently, the authors of [20] have designed a cathodic protection system by overlay of a thin $\mathrm{TiO}_{2}$ film on steel substrate and exposing the system to $\mathrm{UV}$ radiation. The system is attached to a solar panel to store the electrons during bright and sunny days and regenerate the electrons at night and cloudy days. Because of a wide band gap of $3.2 \mathrm{eV}, \mathrm{TiO}_{2}$ serves as an anode without sacrificing itself unlike the zinc and magnesium. While protecting the steel, the film of titanium dioxide surface generates hydroxyl radicals $\left(\mathrm{OH}^{-}\right)$, superoxide anions $\left(\mathrm{O}_{2}{ }^{-}\right)$, and hydrogen peroxide $\left(\mathrm{H}_{2} \mathrm{O}_{2}\right)$ which clean the organic 


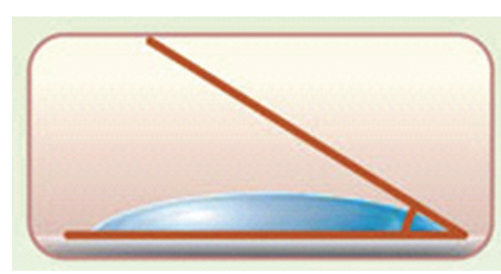

(a)

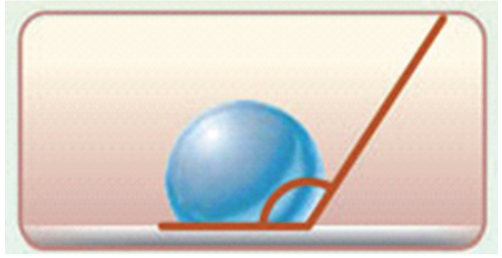

(b)

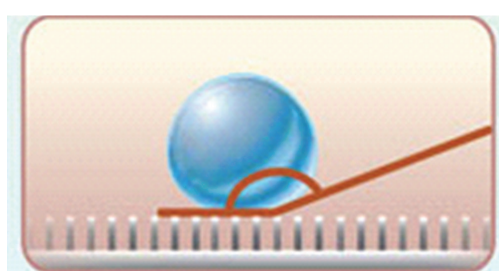

(c)

FIgure 8: (a) Hydrophilic surface: angle less than 30 degrees; (b) Hydrophobic surface: angle greater than 90 degrees; (c) Superhydrophobic surface: angle greater than 150 degrees.

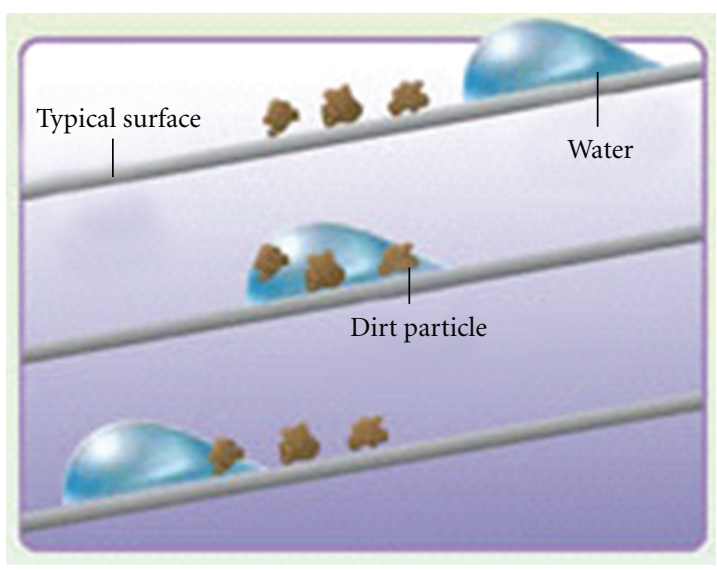

(a)

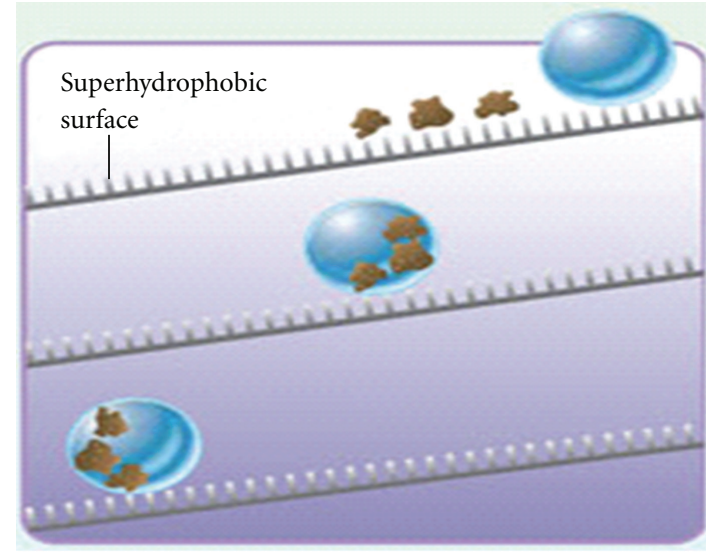

(b)

Figure 9: (a) Drop of water slides across and leaves most dirt particles sticking to the object on a typical surface (one not extremely hydrophilic or hydrophobic); (b) on a superhydrophobic surface, a drop rolls across, picking up dirt and carrying it away.

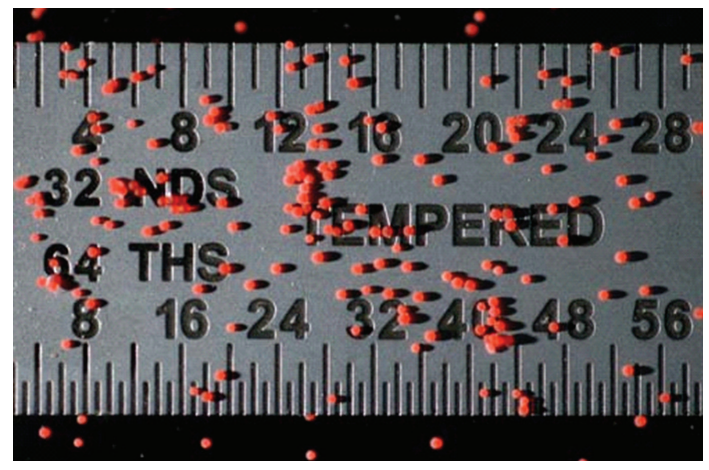

FIGURE 10: Healing-agent-containing microcapsules used in selfhealing polymers. A steel ruler is pictured in the background for reference (Magnus Andersson, University of Illinois).

contamination by their photocatalytic activity as shown in Figure 13. This nonsacrificial galvanic cathodic protection system with added environmental and antibacterial properties offers an alternative to the conventional galvanic cathodic protection system where anodes are consumed and need periodic replacement. The eco-friendly techniques described above need further development; however, they offer a promise of clean corrosion prevention practices without hurting the environment.

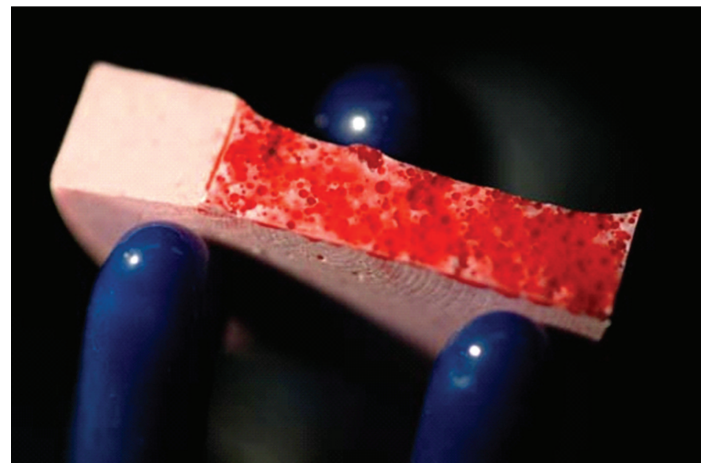

Figure 11: Close-up image of one-half of a self-healing epoxy specimen after it has been fractured into two pieces (Magnus Andersson, University of Illinois).

\section{Conclusion}

With the revolutionary progress in industrialization and urbanization witnessed in recent years the intensity of air pollution and greenhouse gases has increased in alarming proportion. Both materials and mankind are therefore exposed to enhanced risk. New strategies to preserve materials and other resources need to be developed to enhance the life of materials while maintaining the environment green. 


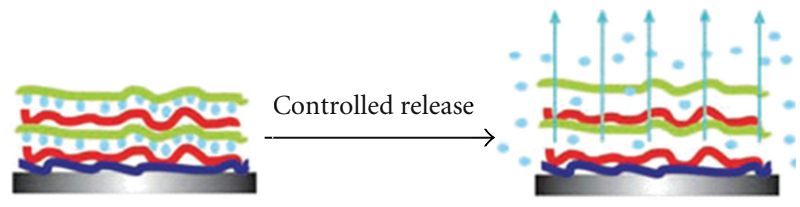

(a)

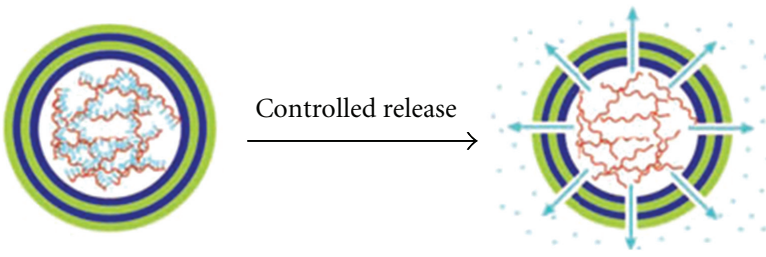

(b)

FIGURE 12: Schematic illustration of the entrapment/release of active materials: (a) Active material is embedded in the "passive" matrix of the coating; (b) active material is encapsulated into nanocontainers with a shell possessing controlled permeability properties.

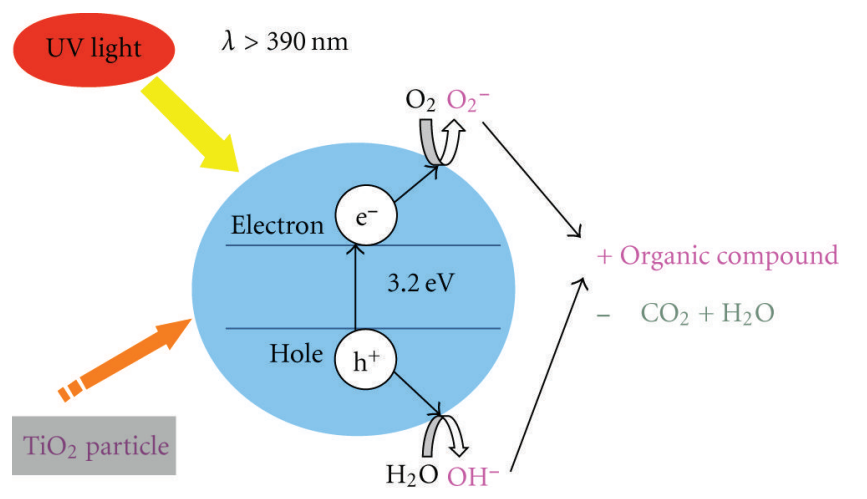

$\mathrm{O}_{2}+\mathrm{e}^{-}-\mathrm{O}_{2}^{-}$

$\mathrm{H}_{2} \mathrm{O}+\mathrm{h}^{+}-\mathrm{OH}^{-}$

$\mathrm{O}_{2}^{-}+\mathrm{OH}^{-}+$Organic compound $-\mathrm{CO}_{2}+\mathrm{H}_{2} \mathrm{O}$

FIGURE 13: Cathodic protection system using UV radiation.

The existing corrosion solutions need to be transformed to green solutions by developing eco-friendly techniques. It has been shown how the corrosion protection methods such as inhibitor treatment, metallic-nonmetallic coatings, paints, and cathodic protection can be made greener by utilizing emerging techniques such as nano- and microtechnologies. Some work on eco-friendly techniques reported in the paper has shown how some of the traditional corrosion protection techniques can be transformed to eco-friendly techniques. It is just the beginning for a hopeful tomorrow.

\section{Acknowledgment}

The authors would like to acknowledge the support provided for this work by King Abdulaziz City for Science and Technology (KACST), Saudi Arabia, at King Fahd University of Petroleum \& Minerals (KFUPM), Saudi Arabia, under
National Science, Technology and Innovation Plan (NSTIP) with the Project no. 08-NAN93-4.

\section{References}

[1] "The Asian Brown Cloud: Climate and Other Environmental Impacts," UNEP Assessment Report, 2002, http://www.rrcap .unep.org/issues/air/impactstudy/index.cfm/.

[2] V. Ramanathan, M. V. Ramana, G. Roberts et al., "Warming trends in Asia amplified by brown cloud solar absorption," Nature, vol. 448, no. 7153, pp. 575-578, 2007.

[3] "Other effects on mankind: Air pollution speeds up corrosion," Air Quality, Air Pollution \& Climate Secretariat, Sweden, 2011, http://www.airclim.org/airQuality/sub4_3.php.

[4] C. S. Uyguner and M. Bekbolet, "Contribution of metal species to the heterogeneous photocatalytic degradation of natural organic matter," International Journal of Photoenergy, vol. 2007, Article ID 23156, 8 pages, 2007.

[5] http://earthtrends.wri.org/pdf_library/country_profiles/cli_ cou_682.pdf/.

[6] "Desalination Project Heads to Final Coastal Commission Hearing," Poseidon Resources, Desalination Update, no. 14, 2008, http://www.workingwithwater.net/.

[7] G. Johnson, L. Stowell, and M. Monroe, "A Comparison of conventional treatment methodsand VSEP, a vibrating membrane filtration system," in Proceedings of the El Paso Desalination Conference, El Paso Texas, VSEP Treatment of RO Reject from Brackish Well Water, New Logic Research, March 2006.

[8] http://www.vsep.com/downloads/index.html.

[9] Z. Ahmad and M. Ahsan, "Nanopaint for desert environments," Materials Performance, vol. 45, no. 11, pp. 30-33, 2006.

[10] Z. Ahmad and M. Ahsan, "Corrosion studies on the plasmasprayed nanostructured titanium dioxide coatings," AntiCorrosion Methods and Materials, vol. 56, no. 4, pp. 187-195, 2009.

[11] Z. Ahmad and B. J. Aleem, "Erosion-corrosion behavior of DAS titanium di-oxide coatings on neutral sodium chloride solution," Nace Corrosion, vol. 65, no. 9, 2009.

[12] B. Qian and Z. Shen, "Fabrication of superhydrophobic surfaces by dislocation-selective chemical etching on aluminum, copper, and zinc substrates," Langmuir, vol. 21, no. 20, pp. 9007-9009, 2005.

[13] Z. Ahmad, S. Rehman, and M. Ahsan, "Methods of fabrication of superhydrophobic engineering surfaces: a review," International Review of Mechanical Engineering, vol. 3, no. 3, pp. 312321, 2009.

[14] M. H. Jin, X. J. Feng, J. M. Xi et al., "Super-hydrophobic PDMS surface with ultra-low adhesive force," Macromolecular Rapid Communications, vol. 26, no. 22, pp. 1805-1809, 2005.

[15] B. Qian and Z. Shen, "Fabrication of superhydrophobic surfaces by dislocation-selective chemical etching on aluminum, copper, and zinc substrates," Langmuir, vol. 21, no. 20, pp. 9007-9009, 2005.

[16] Z. G. Guo, F. Zhou, J. C. Hao, and W. M. Liu, "Stable biomimetic super-hydrophobic engineering materials," Journal of the American Chemical Society, vol. 127, no. 45, pp. 15670-15671, 2005.

[17] X. Wu, G. L. Zheng, and D. Wu, "Fabrication of superhydrophobic surfaces from micro structured $\mathrm{ZnO}$-based surfaces via a wet-chemical route," Langmuir, vol. 21, no. 7, pp. 26652667, 2005. 
[18] L. Feng, Z. Zhang, Z. Mai et al., "A super-hydrophobic and super-oleophilic coating mesh film for the separation of oil and water," Angewandte Chemie, vol. 43, no. 15, pp. 20122014, 2004.

[19] S. O. Moussa and M. G. Hocking, "The photo-inhibition of localized corrosion of 304 stainless steel in sodium chloride environment," Corrosion Science, vol. 43, no. 11, pp. 20372047, 2001.

[20] I. Ahmed, Z. Ahmad, F. Patel, and M. Shuja Khan, "A photo-cathodic protection system utilizing UV radiations," International Journal of Engineering and Technology, vol. 11, no. 1, pp. 197-202, 2011. 

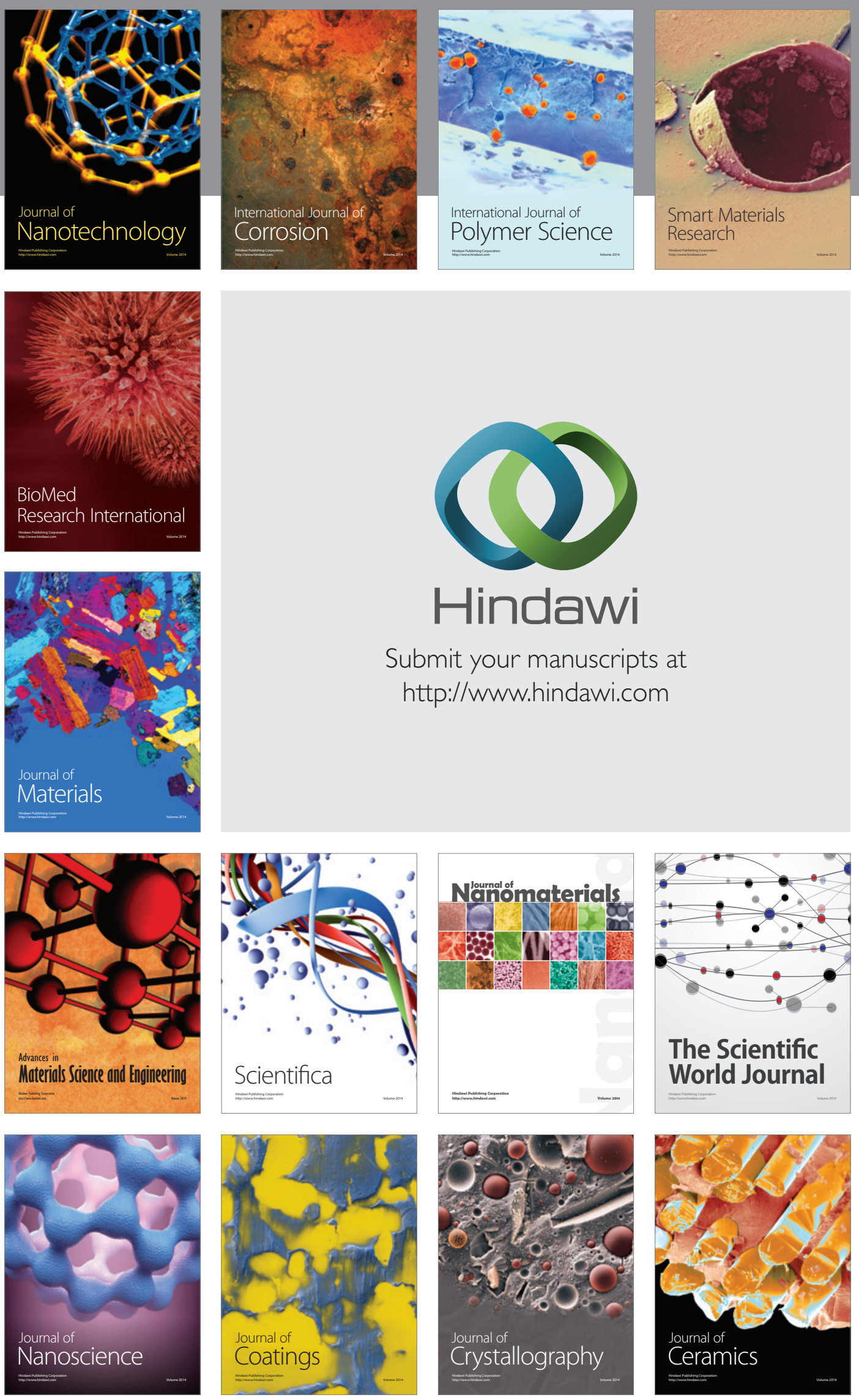

The Scientific World Journal

Submit your manuscripts at

http://www.hindawi.com

\section{World Journal}

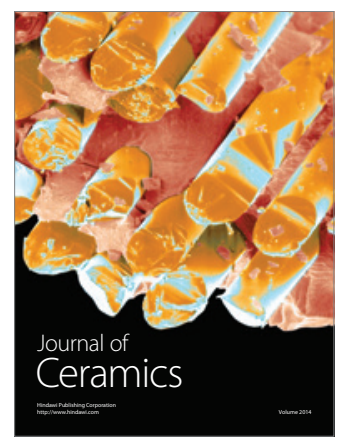

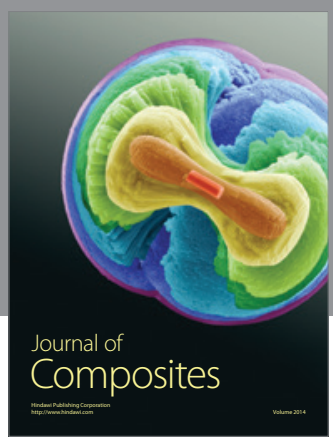
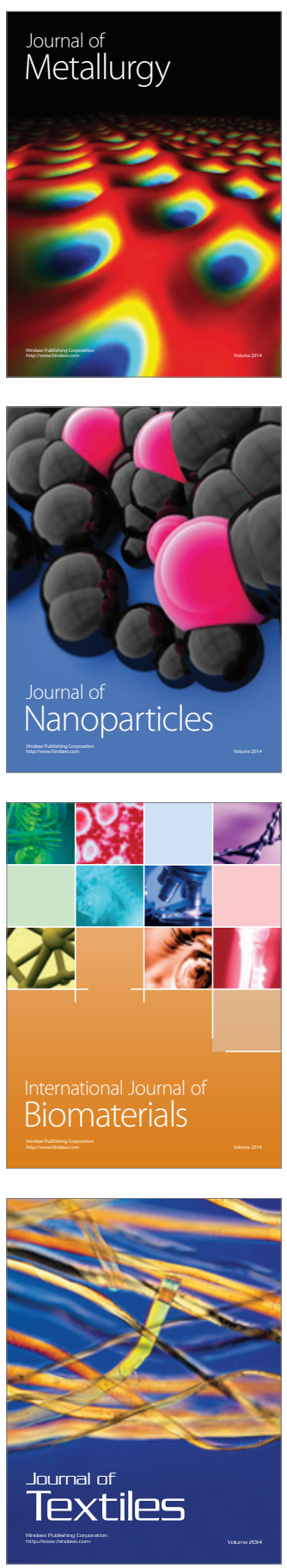